\section{Long-Term Maintenance of Primary Cell Cultures from Ovarian Tissue of Kuruma Prawn Penaeus japonicus}

\author{
Minoru Maeda ${ }^{1 *}$, Ken-ichi Kusumoto ${ }^{2}$, \\ Eiichi Mizuki $^{2}$, Toshiaki Itami ${ }^{3}$ \\ and Michio $\mathrm{Ohba}^{4}$ \\ ${ }^{1}$ Kyushu Medical Co., Ltd., Fukuoka Bio Incubation Center, \\ Kurume, Fukuoka 839-0864, Japan \\ ${ }^{2}$ Biotechnology and Food Research Institute, Fukuoka \\ Industrial Technology Center, Kurume, Fukuoka 839-0861, \\ Japan \\ ${ }^{3}$ Department of Biological Production and Environmental \\ Science, Faculty of Agriculture, University of Miyazaki, \\ Miyazaki 889-2192, Japan \\ ${ }^{4}$ Graduate School of Agriculture, Kyushu University, \\ Fukuoka 812-8581, Japan
}

(Received July 25, 2005)

\begin{abstract}
The long-term maintenance of primary cell cultures from ovarian tissue of kuruma prawn Penaeus japonicus was examined in modified Leibovitz-15 medium supplemented with four growth factors (epidermal growth factor, basic-fibroblast growth factor, insulin and ciliary neurotrophic factor) and an antioxidant (2-mercaptoethanol; 2$\mathrm{ME}$ ). This medium allowed the primary-cultured cells to survive for a long period up to six months, while only for 45 days in the absence of the five supplements. Efficacy assessment for each supplement revealed that only 2-ME facilitated long-term maintenance of cell sheets.
\end{abstract}

Key words: Penaeus japonicus, primary cell culture, ovary, mercaptoethanol, growth factor

Penaeid shrimp is among the commercially important crustaceans in aquaculture. For the last two decades, intensive efforts have been made to establish continuous shrimp cell lines that facilitate biochemical, physiological and virological studies of penaeid shrimp. Recently, a continuous cell line has been established from the freshwater crayfish Orconectes limosus ${ }^{1}$. As yet, however, no cell lines are available from marine crustaceans.

Chen and $\mathrm{Kou}^{2)}$ first reported that the primary cell cultures from lymphoid organ of black tiger shrimp Penaeus monodon supported the replication of the monodon-type baculovirus. This was followed by

\footnotetext{
* Corresponding author

E-mail: maeda@kmed.co.jp
}

observations that the in vitro primary cultures of lymphoid organ from other penaeid shrimp were also permissive for certain shrimp viruses ${ }^{3-5)}$.

In a preceding report, Maeda et $a .^{6)}$ developed a new technique for primary cell culture from ovarian tissue of kuruma prawn $P$. japonicus in an attempt to use it for the studies of white spot syndrome virus (WSSV) infection. Recently, Maeda et al. ${ }^{7)}$ have also demonstrated that the established primary cell culture from ovarian tissue was permissive for replication of WSSV. This technique proved highly effective for production of WSSV-susceptible monolayer cultures. However, the cell culture longevity was relatively short, not exceeding 45 days. In this report, four growth factors and an antioxidant are examined for their effect on the long-term maintenance of primary culture of cells isolated from ovarian tissue.

\section{Materials and Methods}

\section{Primary cell culture}

Primary cell culture was done according to the method of Maeda et al. ${ }^{6)}$ with some modifications. Briefly, the ovary was extirpated from the mature prawn, and washed three times with double strength $(2 \times)$ Leibovitz-15 (L-15) medium containing penicillin $(1,000$ units $/ \mathrm{mL})$ and streptomycin $(1,000 \mu \mathrm{g} / \mathrm{mL})$. Ovarian tissues were cut into 2- to $3-\mathrm{mm}^{3}$ cubes, subjected to digestion with collagenase type $\mathrm{V}$ (Sigma, USA) at $25^{\circ} \mathrm{C}$ for $30 \mathrm{~min}$ to disperse cells, and finally seeded to 24-well plastic plates in $1 \mathrm{~mL}$ of culture medium. The culture medium (575 mosmol $/ \mathrm{kg}$ ) consisted of $2 \times \mathrm{L}-15$ medium supplemented with $10 \%$ fetal bovine serum, glucose ( 1 $\mathrm{g} / \mathrm{L})$, proline $(0.1 \mathrm{~g} / \mathrm{L})$, taurine $(0.1 \mathrm{~g} / \mathrm{L})$, TC-Yeastolate (1 $\mathrm{g} / \mathrm{L})$ and lactalbumin hydrolysate $(1 \mathrm{~g} / \mathrm{L})$. The 24-well plate was centrifuged at $1,000 \times g$ at $4^{\circ} \mathrm{C}$ for $15 \mathrm{~min}$, followed by incubation at $25^{\circ} \mathrm{C}$. At 7-day intervals, $50 \%$ of the culture medium was replaced with fresh medium. Cell conditions were monitored daily under an inverted phase-contrast microscope.

\section{Growth factors and antioxidant}

Growth factors and an antioxidant used were as follows: epidermal growth factor (R\&D Systems, USA), basic-fibroblast growth factor (R\&D Systems), insulin (Sigma), ciliary neurotrophic factor (Sigma), and 2mercaptoethanol (2-ME: Invitrogen, USA). Table 1 shows the final concentrations of respective factors in the culture medium.

\section{Results and Discussion}

Table 1 shows the assessment of efficacy of various factors. Among the factors tested, 2-ME yielded the best cell viability. In the presence of this substance, cultured cells survived for a long period, up to 6 months, and 
Table 1. Effects of growth factors and an antioxidant on the longevity of primary cultures from ovarian tissue of kuruma prawn Penaeus japonicus

\begin{tabular}{|c|c|c|c|c|c|c|c|}
\hline \multirow{3}{*}{ Supplement ${ }^{a}$} & \multirow{3}{*}{ Concentration } & \multicolumn{6}{|c|}{ Cell viability ${ }^{b}$} \\
\hline & & \multicolumn{6}{|c|}{ Months after inoculation } \\
\hline & & 1 & 2 & 3 & 4 & 5 & 6 \\
\hline Epidermal growth factor & $100 \mathrm{ng} / \mathrm{L}$ & ++ & + & - & - & - & - \\
\hline Basic-fibroblast growth factor & $100 \mathrm{ng} / \mathrm{L}$ & ++ & + & - & - & - & - \\
\hline Insulin & $10 \mu \mathrm{g} / \mathrm{L}$ & ++ & + & - & - & - & - \\
\hline Ciliary neurotrophic factor & $10 \mathrm{ng} / \mathrm{L}$ & ++ & + & - & - & - & - \\
\hline 2-Mercaptoethanol & $55 \mu \mathrm{M}$ & ++ & ++ & ++ & + & + & + \\
\hline Mixture of the 5 supplements & & ++ & ++ & ++ & + & + & + \\
\hline Control (no supplement) & & ++ & + & - & - & - & - \\
\hline
\end{tabular}

${ }^{a}$ Culture medium: double strength of $\mathrm{L}-15$ supplemented with $10 \%$ FBS, glucose $(1 \mathrm{~g} / \mathrm{L})$, proline $(0.1 \mathrm{~g} / \mathrm{L})$, taurine $(0.1 \mathrm{~g} / \mathrm{L})$, TC-Yeastolate $(1 \mathrm{~g} / \mathrm{L})$ and lactalbumin hydrolysate $(1 \mathrm{~g} / \mathrm{L})$.

${ }^{b}$ Relative viability was graded as follows. (++) Localized monolayer on the surface of flask bottom. (+) Small monolayer, viable cells or cell clump, adhering to the flask bottom, were evident; however, cell growth was not observed. (-) Few cells adhered to the flask bottom.

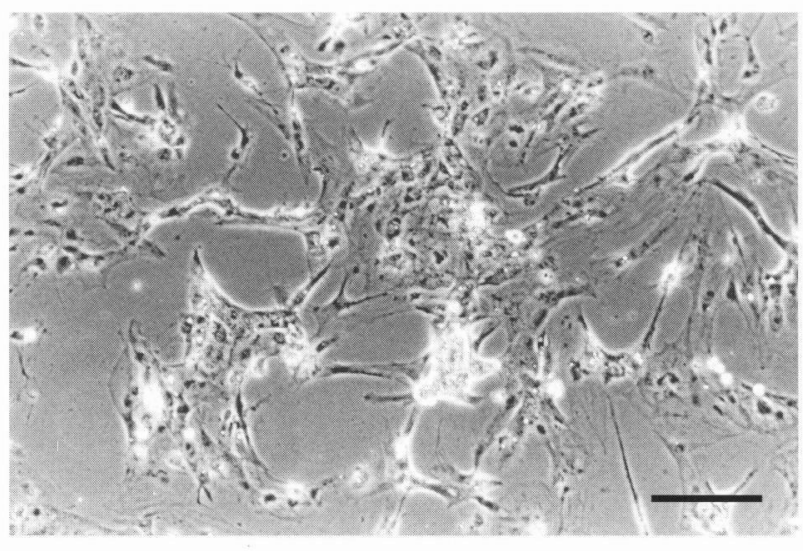

Fig. 1. Photograph of a 120-day-old primary cell culture from ovarian tissue of kuruma prawn Penaeus japonicus. The culture was maintained in the presence of 2 mercaptoethanol. Scale bar $=100 \mu \mathrm{m}$.

the intact cell-monolayer sheets could be maintained for 3 months. Most cells became shrunk on 6 month after initiation of cell culture, and finally were detached from the surface of the plate. Fig. 1 shows a 120-day-old primary cell culture from ovarian tissue maintained in the presence of 2-ME. Subculture of cells through flask-toflask passage was not successful in the present study. This is likely due to cell damages caused by enzymatic or mechanical detachment of primary-culturecell sheets from the surface of the plate. As shown in Table 1, four other factors exhibited no significant effects on the longevity of primary-cultured cells.

Previous reports have shown that growth factors of mammalian cells enhanced the cell viability in primary cell culture of penaeid shrimp. Hsu et al. ${ }^{8)}$ showed that basic-fibroblast growth factor enhanced the in vitro growth of cells from black tiger shrimp, leading to subcultures over 90 passages. Nadala et al. ${ }^{9)}$ also reported that the addition of epidermal growth factor markedly enhanced the cell growth in primary cultures from blue shrimp Penaeus stylirostris, and white shrimp Penaeus vannamei. In our experiments, however, four growth factors including the above 2 factors had no effect on viability of primary-cultured cells of kuruma prawn. These results are in good agreement with earlier observations $^{10)}$ that none of growth factors tested induced better cell growth in primary culture of lymphoid organs of kuruma prawn.

Of the five supplements tested, only 2-ME supported high cell viability in primary-cultured cells from ovarian tissue. Cell-culture longevity ( $>6$ months) obtained here was far more greater than that obtained in our previous study ${ }^{6)}$. This is the first report that the presence of 2-ME highly supports the in vitro viability of penaeid shrimp cells. It is widely accepted that $\beta$-mercaptoethanol $(=2-\mathrm{ME})$ protects cells from oxidative damages. Pruett et al. ${ }^{11)}$ reported that this antioxidant increased survival ratio and cell growth in murine lymphocytes with a doubling of protein synthesis at maximal cell growth. Takahashi et al. ${ }^{12)}$ also reported that $\beta$ mercaptoethanol had a protective effect in embryonic development against oxidative stress, promoting the uptake of cystine from culture medium into bovine embryos. According to Toohey ${ }^{13)}$, cysteine is easily oxidized in culture medium, forming cystine, a dimer of cysteine, even under usual culture conditions. Interestingly, certain types of cells such as lymphocytes have difficulties in utilizing cystine, leading to the lowered cell proliferation and decreased intracellular glutathione concentration $^{14)}$. It is now well established that the glutathione plays an important role in keeping intracellular redox state for protecting cells from oxidative injuries, and its synthesis is highly dependent on the availability of cysteine in the medium ${ }^{15}$ ).

Microscopic observations revealed that the mitotic figures was not evident for one month after initiation of cell culture; however, the cell condition seemed normal for long period. This suggests that 2-ME does not 
stimulate cell proliferation, but protect cultured cells against oxidative stress. Future works will include biochemical analysis how 2-ME supports the long in vitro viability of penaeid shrimp cells.

\section{References}

1) Neuman, T., H. E. Kaiser and F. W. Rath (2000): In Vivo, 14, 691-698. 2) Chen, S. N. and G. H. Kou (1989): J. Fish Dis., 12, 73-76. 3) Lu, Y., P. C. Tapay, P. C. Loh, J. A. Brock and R. Gose (1995): J. Virol. Methods, 52, 231-236. 4) Tapay, L. M., Y. Lu, R. B. Gose, E. C. B. Nadala, J. A. Brock and P. C. Loh (1997): J. Virol. Methods, 64, 37-41. 5) Wang, C. H., H. N. Yang, C. Y. Tang, C. H. Lu, G. H. Kou and C. F. Lo (2000): Dis. Aquat. Org., 41, 91-104. 6) Maeda, M., E. Mizuki, T. Itami and M. Ohba (2003): In Vitro Cell. Dev. Biol. Anim., 39, 208212. 7) Maeda, M., H. Saitoh, E. Mizuki, T. Itami and M. Ohba (2004): J. Virol. Methods, 116, 89-94. 8) Hsu, Y. L., Y. H. Yang, Y. C. Chen, M. C. Tung, J. L. Wu, M. H. Engelking and J. C. Leong (1995): Aquaculture, 136, 43-55. 9) Nadara, E. C. B., Y. Lu and P. C. Loh (1993): In Vitro Cell. Dev. Biol., 29A, 620-622. 10) Itami, T., M. Maeda, M. Kondo and $Y$. Takahashi (1999): Methods Cell Sci., 21, 237-244. 11) Pruett, S. B., N. Obiri and J. L. Kiel (1989): J. Cell. Physiol., 141, 4045. 12) Takahashi, M., T. Nagai, N. Okamura, H. Takahashi and A. Okano (2002): Biol. Reprod., 6, 562-567. 13) Toohey, J. I. (1975): Proc. Natl. Acad. Sci. U.S.A., 72, 73-77. 14) Ishii, T., S. Bannai and Y. Sugita (1981): J. Biol. Chem., 256, 1238712392. 15) Sagara, J., K. Miura and S. Bannai (1993): J. Neurochem. 61, 1667-1671. 